\title{
An Electron-Accepting Chromophore Based on Fluorene and Naphthalenediimide Building Blocks for Solution-Processable Bulk Heterojunction Devices
}

\author{
Akhil Gupta, ${ }^{*[a]}$ Xizu Wang, ${ }^{[b]}$ Doli Srivani, ${ }^{[c]}$ Ben Alford ${ }^{[a]}$ Vijila Chellappan, ${ }^{[b]}$ Ante Bilic, ${ }^{[d]}$ \\ Hemlata Patil, ${ }^{[a]}$ Lathe A. Jones, ${ }^{[a, e]}$ Sidhanath V. Bhosale, ${ }^{*[c]}$ Prashant Sonar, ${ }^{*[f]}$ and \\ Sheshanath V. Bhosale*[a]
}

Abstract: We have designed, synthesized and utilized a new non-fullerene electron acceptor, 9,9'-(9,9-dioctyl-9H-fluorene2,7-diyl)bis(2,7-dioctyl-4-(octylamino)benzo[Imn][3,8]phenanthroline-1,3,6,8(2H,7H)-tetraone) (B2), for use in solutionprocessable bulk-heterojunction devices. B2 is based on a central fluorene moiety, which was capped at both ends with an electron-accepting naphthalenediimide functionality.
B2 exhibited excellent solubility $\left(>30 \mathrm{mg} \mathrm{mL}^{-1}\right.$ in chloroform), high thermal and photochemical stability, and appropriate energy levels for use with the classical polymer donor regioregular poly(3-hexylthiophene). A power conversion efficiency of $1.16 \%$ was achieved for primitive bulk-heterojunction devices with a high fill factor of approximately $54 \%$.

\section{Introduction}

Over the past two decades, bulk-heterojunction (BHJ) solar cells have attracted a significant amount of attention from re-

[a] Dr. A. Gupta, Dr. B. Alford, H. Patil, Dr. L. A. Jones, Dr. S. V. Bhosale School of Applied Sciences

RMIT University

GPO Box 2476, Melbourne, Victoria 3001 (Australia)

E-mail: sheshanath.bhosale@rmit.edu.au akhilgk15@gmail.com

[b] X. Wang, ${ }^{+}$Dr. V. Chellappan

Institute of Materials Research and Engineering (IMRE)

Agency for Science, Technology and Research ( $A^{*}$ STAR)

3 Research Link, Singapore 117602 (Singapore)

[c] D. Srivani, ${ }^{+}$Dr. S. V. Bhosale

Polymers and Functional Material Division

CSIR-Indian Institute of Chemical Technology

Hyderabad 500 007, Telangana (India)

E-mail:bhosale@iict.res.in

[d] Dr. A. Bilic

Virtual Nanoscience Lab, CSIRO Manufacturing Parkville, Victoria 3052 (Australia)

[e] Dr. L. A. Jones

Centre for Advanced Materials and Industrial Chemistry RMIT University

Melbourne, Victoria 3001 (Australia)

[f] Dr. P. Sonar

Chemistry, Physics and Mechanical Engineering School

Queensland University of Technology

GPO Box 2434, Brisbane, Queensland 4001 (Australia)

E-mail: sonar.prashant@qut.edu.au

$\left.{ }^{[+}\right]$These authors contributed equally to this work.

Supporting information for this article is available on the WWW under http://dx.doi.org/10.1002/ajoc.201500112. searchers in academia and industry. These solar cells are promising candidates for the production of renewable energy to help meet energy demands. Furthermore, solution-processed $\mathrm{BHJ}$ devices are being developed to make interpenetrating networks with large donor-acceptor interfacial areas. Factors such as flexibility, low-cost and large area with long-term stability are also important for their commercial viability. ${ }^{[1]} \mathrm{A}$ power conversion efficiency (PCE) of $>10 \%$ has been reported for solution-processed $\mathrm{BHJ}$ devices based on a polymer tandem solar cell. ${ }^{[2]}$ Such a high efficiency is a result of the development of a novel, rich class of electron-donor materials that demonstrate improved optoelectronic properties, such as light harvesting, and favorable highest occupied molecular orbital (HOMO) and lowest unoccupied molecular orbital (LUMO) energy level tunability, which match strongly those of electron acceptors. ${ }^{[3]}$ Most researchers in this area are developing new donor materials; this is thought to be the key to improving $\mathrm{BHJ}$ device performance. However, as per our understanding, electron acceptors must be perceived as equally important as donor materials. However, the design and development of electron-accepting chromophores has trailed behind that of their donor counterparts. Therefore, the design and development of new electron-acceptor materials has become a critical research topic.

Fullerenes and their derivatives, such as $[6,6]-$ phenyl- $C_{61}$-butyric acid methyl ester $\left(\mathrm{PC}_{61} \mathrm{BM}\right)$ and its $C_{71}$ analogue $P C_{71} \mathrm{BM}$, are undoubtedly the best examples of conventional electronacceptor materials, principally because of their superior electron affinity, good electron mobility and good interaction with donor materials. ${ }^{[4]}$ However, the use of fullerene acceptors is limited by a number of disadvantages such as weak absorption 
in the visible spectrum, high cost, restricted electronic tuning, cumbersome synthesis and large electron affinity that can result in low open-circuit voltages $\left(V_{o c}\right){ }^{[5]}$ Therefore, the challenge remains to develop new non-fullerene electron acceptors that not only possess the encouraging properties of fullerene derivatives, but also overcome their limitations. The following important features should be considered in the design of new non-fullerene electron-acceptor materials: 1) facile synthesis, 2) strong and broad absorption, 3) high charge-carrier mobility, 4) solubility, and 5) controllable frontier orbital energy levels. ${ }^{[6]}$ Recent reports published by Yan. et al., Sonar et al., and Lin and Zhan show the energetic efforts of various research groups toward the development of non-fullerene acceptors. $^{[7]}$ These efforts have yielded efficiencies of up to $4 \%$ with few accepting chromophores, although many other targets have been scrutinized. ${ }^{[8]}$

Despite the advancement of electron acceptors, substantial scope still exists to develop new non-fullerene acceptors that possess strong absorption, good photochemical stability, excellent solubility and tuned optical energy levels matching those of donor semiconducting components. Towards this goal, functionalities such as fluorene (FL) and naphthalenediimide (NDI) have shown potential to be used as versatile building blocks for the development of non-fullerene acceptors. Recently, we and others have been successful in demonstrating the use of such functionalities for the development of non-fullerene electron acceptors. ${ }^{[8,1,1,9]}$ Fluorene has shown particular promise to be used in conjunction with versatile electron-deficient building blocks to generate highly conjugated structures. ${ }^{[8, j, 1]}$

Realizing the importance of these developments, we anticipated the combined use of FL and NDI functionalities to generate target materials that possess extended conjugation along with structural planarity, chemical and thermal stability, and excellent solubility. Regarding the solution processability of our target chromophore, we envisaged using peripheral lipophilic chains on the terminal NDI moieties. This was achieved by choosing $n$-octylamine groups containing a conventional donor nitrogen atom. Such donor atoms have been used to fine tune the energy levels of optoelectronic materials. ${ }^{[10]}$ Even though there are a great deal of amine functionalities available, $n$-octylamine was the preferred choice from a molecular symmetry point of view. By using these alkyl chains, which were in addition to the lypophilic moieties already present on FL and NDI functionalities, we were able to generate a highly conjugated, symmetrical target material comprising $\mathrm{FL}$ as the central core capped by NDI units carrying peripheral chains as terminal substituents.

Evidently, the presence of such alkyl chains not only enhances the solubility of the target chromophore, but also affords excellent film-forming qualities without crystallization occurring in the film. Furthermore, the presence of hydrogen atoms at the terminal positions of NDI functionalities may reduce steric interactions. The structure of the material reported herein, 9,9'-(9,9-dioctyl-9H-fluorene-2,7-diyl)bis[2,7-dioctyl-4(octylamino)benzo[Imn][3,8]phenanthroline-1,3,6,8(2H,7H)-tetraone] (B2) is shown in Scheme 1. An initial assessment of B2 as an "n-type" material was carried out by using it in a solu-

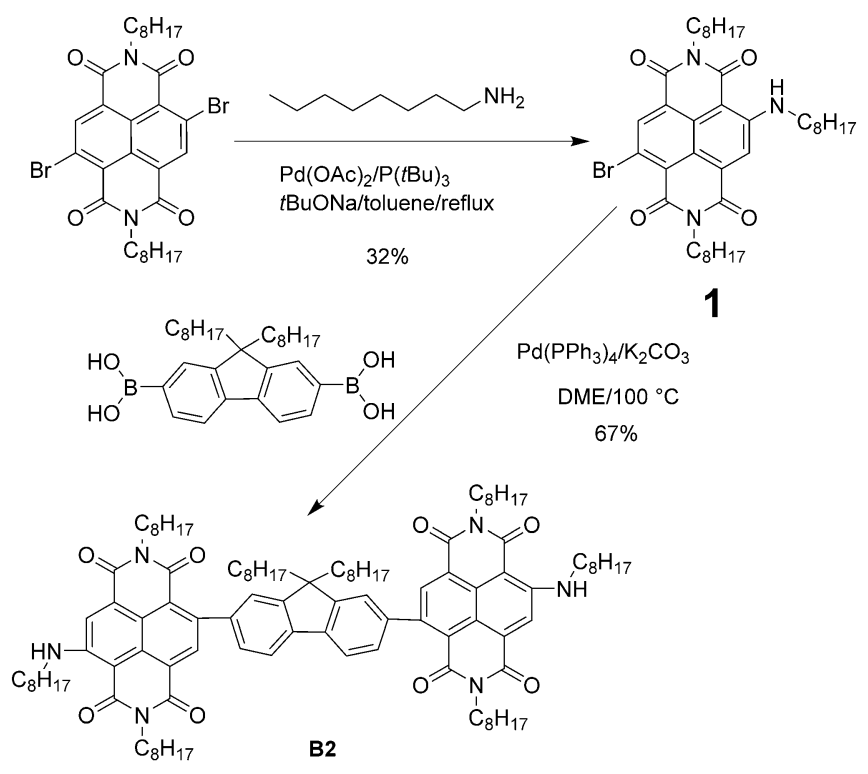

Scheme 1. The synthesis of B2.

tion-processable $\mathrm{BHJ}$ device along with the conventional polymer donor regioregular poly(3-hexylthiophene) (rr-P3HT). A BHJ device based on an rr-P3HT-B2 blend (1:1 w/w) exhibited a PCE as high as $1.16 \%$ with a high fill factor (FF) of $54.3 \%$. To our knowledge, B2 is the first non-fullerene electron acceptor that incorporates $\mathrm{FL}$ and NDI functionalities. The design and development of B2 is a continuation of our research on materials for organic electronic applications. ${ }^{[11]}$

\section{Results and Discussion}

Compound B2 was synthesized in a straightforward manner using a high-yielding Suzuki coupling reaction between the commercially available (9,9-dioctyl-9H-fluorene-2,7-diyl)diboronic acid and the mono-bromo derivative, 4-bromo-2,7-dioctyl9-(octylamino)benzo[Imn][3,8]phenanthroline-1,3,6,8(2H,7H)-tetraone $(1 ;$ Scheme 1$)$. The reaction was carried out in dimethoxyethane at $100^{\circ} \mathrm{C}$ for $24 \mathrm{~h}$ using $\mathrm{K}_{2} \mathrm{CO}_{3}$ as a base and tetrakis(triphenylphosphine)palladium(0) $\left[\mathrm{Pd}\left(\mathrm{PPh}_{3}\right)_{4}\right]$ as the catalyst. B2 was purified by silica gel column chromatography and was characterized using ${ }^{1} \mathrm{H}$ and ${ }^{13} \mathrm{C}$ NMR spectroscopy and elemental analysis.

As predicted, B2 showed excellent solubility in a variety of common organic solvents, such as chlorobenzene, chloroform, dichlorobenzene and toluene (e.g., $>30 \mathrm{mg} \mathrm{mL}^{-1}$ in chloroform), due to the presence of eight lipophilic octyl chains. High solubility of organic semiconducting materials is absolutely required for the fabrication of large-area, roll-to-roll solution-processable printable organic solar cells and B2 satisfies this condition. Thermogravimetric analysis (TGA) of $\mathbf{B} 2$ revealed a $5 \%$ weight loss at $>400{ }^{\circ} \mathrm{C}$, which clearly indicates the excellent thermal stability of B2. This observation strongly supports the high-temperature annealing of P3HT-B2 devices and is also consistent with differential scanning calorimetry (DSC) analysis of B2, which revealed a melting temperature of around $230^{\circ} \mathrm{C}$ (Figure S4 in the Supporting Information). 


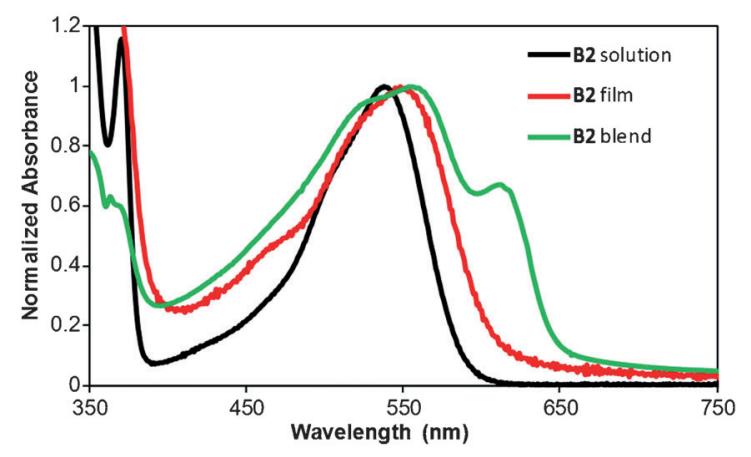

Figure 1. UV/Vis absorption spectra of B2 in chloroform solution, as a pristine film, and as a 1:1 P3HT-B2 solid-state blend.

The optical properties of the acceptor B2 were studied in solution and in the solid state by UV/vis spectroscopy (Figure 1). For the solution study, B2 was dissolved in chloroform, whereas for the thin film, the chloroform solution was spin-coated onto a glass substrate. In solution, an absorption maximum $\left(\lambda_{\max }\right)$ at $538 \mathrm{~nm}\left(\varepsilon=63400 \mathrm{M}^{-1} \mathrm{~cm}^{-1}\right)$ with an onset at $612 \mathrm{~nm}$ was measured, whereas a $\lambda_{\max }$ value of $548 \mathrm{~nm}$ with an onset at $635 \mathrm{~nm}$ was measured for the thin solid film. The thin-film absorption spectrum of B2 showed a bathochromic shift of about $10 \mathrm{~nm}$ compared with its solution spectrum.

In order to study the photoluminescence quenching behavior of the $\mathbf{B 2}$ acceptor, we prepared a blend of P3HT and B2 $(1: 1 \mathrm{w} / \mathrm{w})$ and then spin coated as a thin film. This film clearly exhibited quenching (Figure 2), which is a classical qualitative test to identify potential non-fullerene acceptors and the result for B2 is consistent with those reported for other acceptor materials. $^{[9]}$

The electrochemical behavior of B2 was investigated using cyclic voltammetry (CV) and photoelectron spectroscopy in air (PESA) techniques. The HOMO energy of B2 was estimated using PESA (Figure S5) and the LUMO energy was calculated by adding the band gap to the HOMO value. The HOMO of B2 is low $(-6.00 \mathrm{eV})$, mainly because of the presence of two strongly electron-withdrawing NDI groups at the ends of central FL. Although the energy levels were measured in the thinfilm state, we conducted CV analysis in order to monitor the presence of multiple reversible reduction waves that can suggest the suitability of $\mathbf{B 2}$ as an acceptor. CV measurements

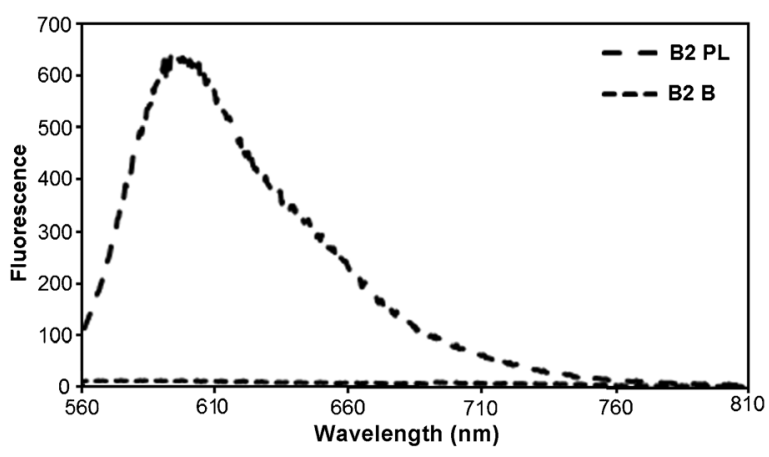

Figure 2. Fluorescence spectra of a pristine film of B2 (B2 PL) along with its 1:1 blend with P3HT as-cast (B2 B), spin-coated from o-dichlorobenzene $\left(\lambda_{\mathrm{ex}}=530 \mathrm{~nm}\right)$. were carried out in freshly distilled dichloromethane with tetra- $n$-butylammonium hexafluorophosphate $\left(n \mathrm{Bu}_{4} \mathrm{NPF}_{6}, 0.1 \mathrm{M}\right)$ as the supporting electrolyte, at a potential scan rate of $50 \mathrm{mV} \mathrm{sec}^{-1}$. B2 exhibited redox behavior with two reversible reduction potential waves and two closely spaced oxidation curves (Figure 3). The two reduction waves formally corre-

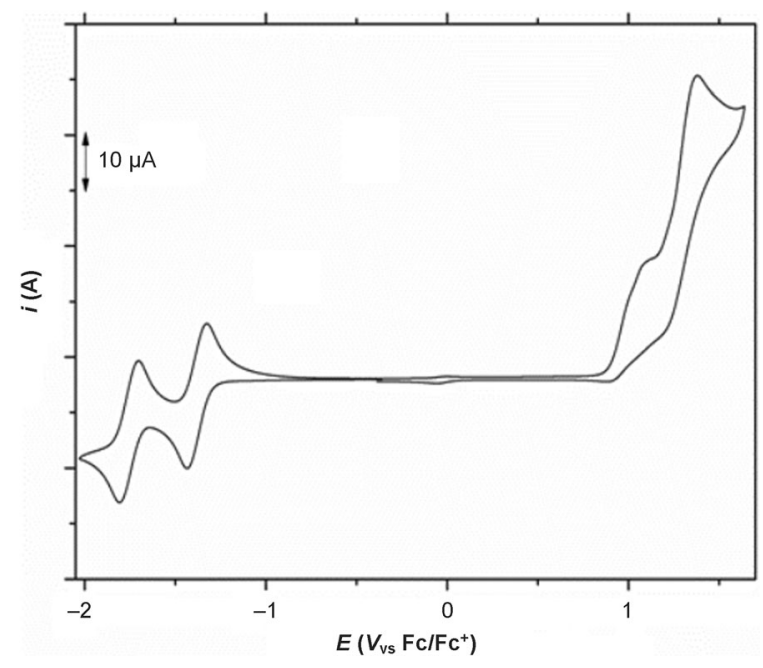

Figure 3. Cyclic voltammogram of B2, measured in freshly distilled dichloromethane at a sweep rate of $50 \mathrm{mV} \mathrm{sec}^{-1}$, showing two reversible reduction potential waves.

spond to the separate reductions of the two terminal NDI functionalities, with the energetic separation of the two reductions due to electronic communication between the NDI groups by conjugation through the central FL. In contrast, the oxidative processes are most likely the direct oxidation of the conjugated backbone of B2, which is typical of conjugated systems. This observation clearly suggests the suitability of B2 as a $n$-type material in solar cells and is a result that is consistent with the literature. ${ }^{[9]}$

In order to study the electron density and its distributions, density functional calculations were performed using the Gaussian 09 suite of programs and the B3LYP/6-311+G(d,p)//B3LYP/ 6-31G(d) level of theory. ${ }^{[12]}$ The HOMO and LUMO orbital density distribution is shown in Figure 4. The HOMO density is consistently occupied over the central FL block, whereas the LUMO density resides over the NDI functionality. Such segregation of HOMO-LUMO densities is vital for optimum band gap and charge transportation, and is ideal for intramolecular charge-transfer transition between donor (push) and acceptor (pull) fragments. The experimental HOMO energy levels of B2 and $\mathrm{PC}_{61} \mathrm{BM}$ were identical, whereas the LUMOs were close enough to suggest the suitability of B2 as a prominent nonfullerene acceptor. Moreover, they were well aligned with those of $\mathrm{P} 3 \mathrm{HT}$ to facilitate electron transfer (see Figure 5 for the energy level diagram). This justifies our rational design approach and also the suitability of $\mathbf{B 2}$ as an electron acceptor in solar cells, a result that is consistent with the CV analysis.

After examining the optoelectronic properties of $\mathbf{B} 2$ and correlating them with those of the conventional $\mathrm{PC}_{61} \mathrm{BM}$ acceptor, 


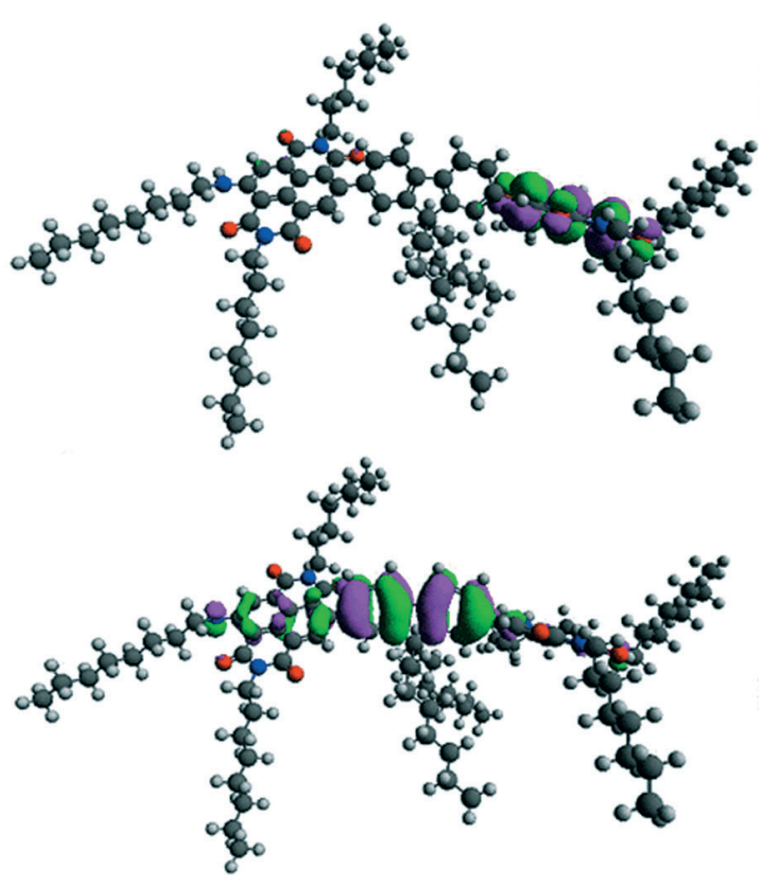

Figure 4. Orbital density distribution for the HOMOs (bottom) and LUMOs (top) of B2. Density functional calculations were performed using the Gaussian 09 suite of programs and the B3LYP/6-311+G(d,p)//B3LYP/6-31G(d) level of theory.

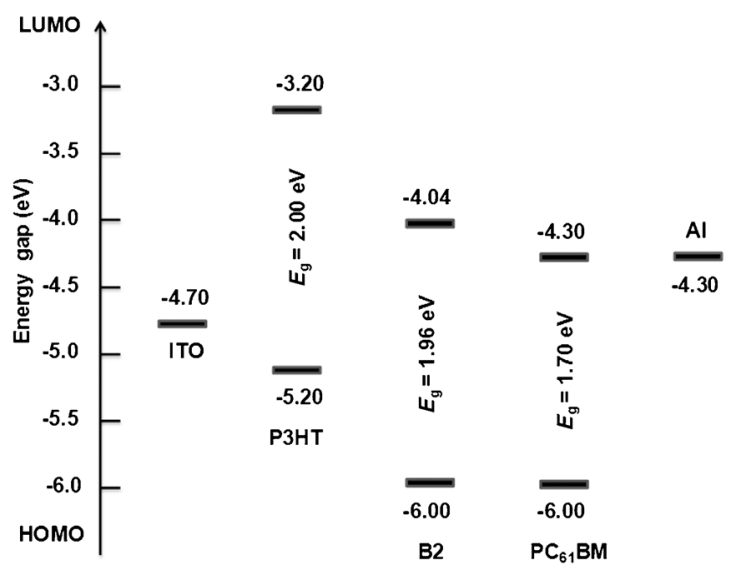

Figure 5. Energy level diagram showing alignments of different architectural components of the $\mathrm{BHJ}$ device.

we attempted to fabricate solution-processable $\mathrm{BHJ}$ devices using the archetypal rr-P3HT as a donor and the newly developed B2 as an acceptor. The blend solution of $p$-type semiconducting rr-P3HT and $n$-type B2 was prepared in o-dichlorobenzene and spin-coated on top of a poly(3,4-ethylenedioxythiophene)-polystyrene sulfonate (PEDOT:PSS) surface as an active layer. In this preliminary study, we selected rr-P3HT as a donor polymer as it is one of the most thoroughly studied and understood polymers in the field of organic photovoltaics, ${ }^{[13]}$ and has the potential to be synthesized using low-cost, highthroughput methods. ${ }^{[14]}$ Furthermore, the simple device architecture was chosen for reasons of processability, stability and reproducibility.
The BHJ device architecture used in this study was ITO (tindoped indium oxide)/PEDOT:PSS (38 nm)/active layer/Al $(100 \mathrm{~nm})$, where the active layer was a 1:1 blend of rr-P3HTB2, spin-coated from o-dichlorobenzene. Lin et al. ${ }^{[8 \mathrm{~d}]}$ and Patil et al. ${ }^{[10]}$ have shown that parameters such as use of high-boiling solvents (preferable for processing), for instance o-dichlorobenzene, and thermal annealing of active layers incorporating small-molecule non-fullerene acceptors are beneficial during the fabrication of $\mathrm{BHJ}$ devices. Using these as prerequisites, we used o-dichlorobenzene as the processing solvent and annealed our blend films at $120^{\circ} \mathrm{C}$ for $5 \mathrm{~min}$. These initial $\mathrm{BHJ}$ devices produced promising performances and the photovoltaic cell parameters $V_{\mathrm{oc}}$, short-circuit current density $\left(U_{\mathrm{sc}}\right), \mathrm{FF}$ and $P C E$, reached $0.58 \mathrm{~V}, 3.69 \mathrm{mAcm}^{-2}, 54.3 \%$ and $1.16 \%$, respectively, at $5 \mathrm{~min}$ post-annealing at $120^{\circ} \mathrm{C}$. It is important to note that all of these devices (a total of six devices were made) afforded $\mathrm{FF}>50 \%$, and that the device parameters reported herein are for the best-performing device. The $J-V$ curve for the high-performing rr-P3HT-B2 BHJ device is shown in Figure 6. For comparison, we also fabricated $\mathrm{P} 3 \mathrm{HT}-\mathrm{PC}_{61} \mathrm{BM}$ devices under similar conditions. By contrast, the maximum $\mathrm{PCE}$ obtained for a device based on $\mathrm{P} 3 \mathrm{HT}-\mathrm{PC}_{61} \mathrm{BM}$ was $2.96 \%$, thus suggesting the reliability of our device strategy (Figure S6). The high FF values of the P3HT-B2 devices are due to the balanced charge-carrier mobility of both holes and electrons. The balanced charge transport with electron/hole mobility leads to a high FF value of up to $54 \%$.

The incident photon-to-current-conversion efficiency (IPCE) measurement of these BHJ devices was broad spectrum, typically over the whole visible range, from 300 to $670 \mathrm{~nm}$. The IPCE value for rr-P3HT-B2 device reached a maximum of approximately $29 \%$ at around $560 \mathrm{~nm}$ (Figure 7).

Although the IPCE value is moderate, the initial performance of this system is significant and promising. Similar effects (lower IPCE and higher FF) have been reported by Lin et al., ${ }^{[89]}$ who used an indacenodithiophene-perylenediimide chromophore as an acceptor with an rr-P3HT donor. By using other donor polymers or small molecules with varying optical band

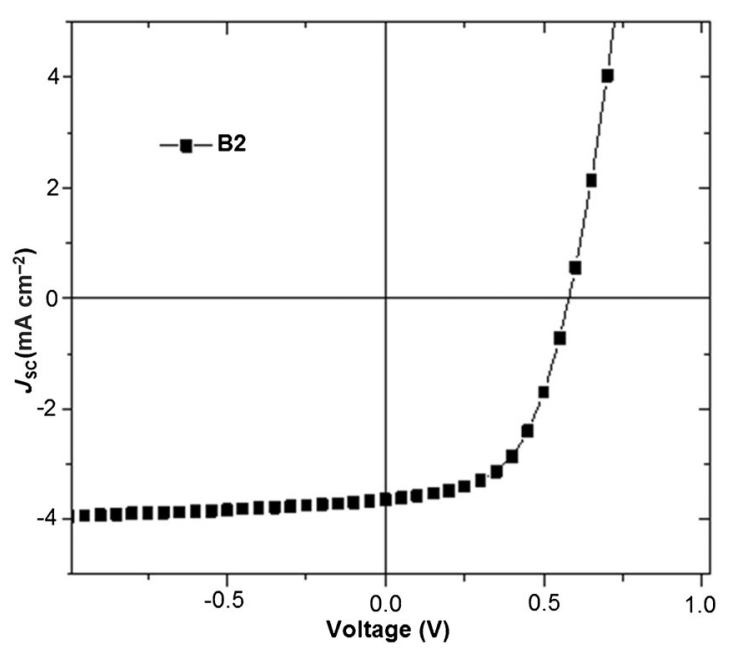

Figure 6. $J-V$ curve for the device based on B2 in blends with rr-P3HT (1:1 $\mathrm{w} / \mathrm{W}$ ) under simulated sunlight (AM1.5 illumination, $1000 \mathrm{~W} \mathrm{~m}^{-2}$ ). 


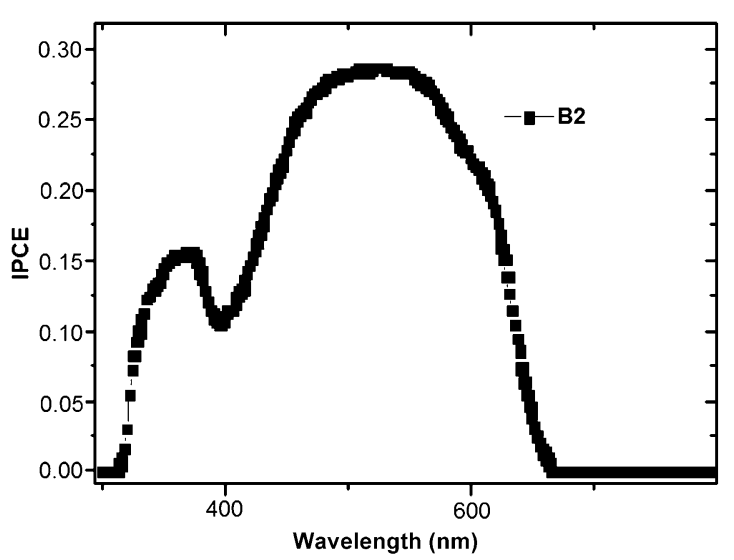

Figure 7. IPCE spectrum measured for the rr-P3HT-B2-based BHJ device.

gaps and different energy levels, the PCE value can be further elevated. The performance can also be improved by using other strategies, such as an effective interlayer, for example, of metal oxide, which can facilitate an efficient charge extraction, or by methods involving solvent additives, solvent annealing or inverted geometries. The solid-state microstructure analysis of B2 and its blends with rr-P3HT was studied by atomic force microscopy (AFM) in the tapping mode. The surface morphology in terms of phase and height of as-cast B2 $(\mathrm{a}, \mathrm{c})$ and the rrP3HT-B2 $(1: 1 \mathrm{w} / \mathrm{w})$ blend annealed at $120^{\circ} \mathrm{C}$ for $5 \mathrm{~min}(\mathrm{~b}, \mathrm{~d})$ is shown in Figure 8.

The morphology of the blend showed intermixing of both donor and acceptor components and the presence of crystalline grains with larger size domains (root-mean square roughness of $7 \mathrm{~nm}$ ). Such morphology is favorable for the formation of an appropriate donor-acceptor interface and the crystalline grains or domains are probably a result of rr-P3HT self-organization, which aids formation of an ordered structure and
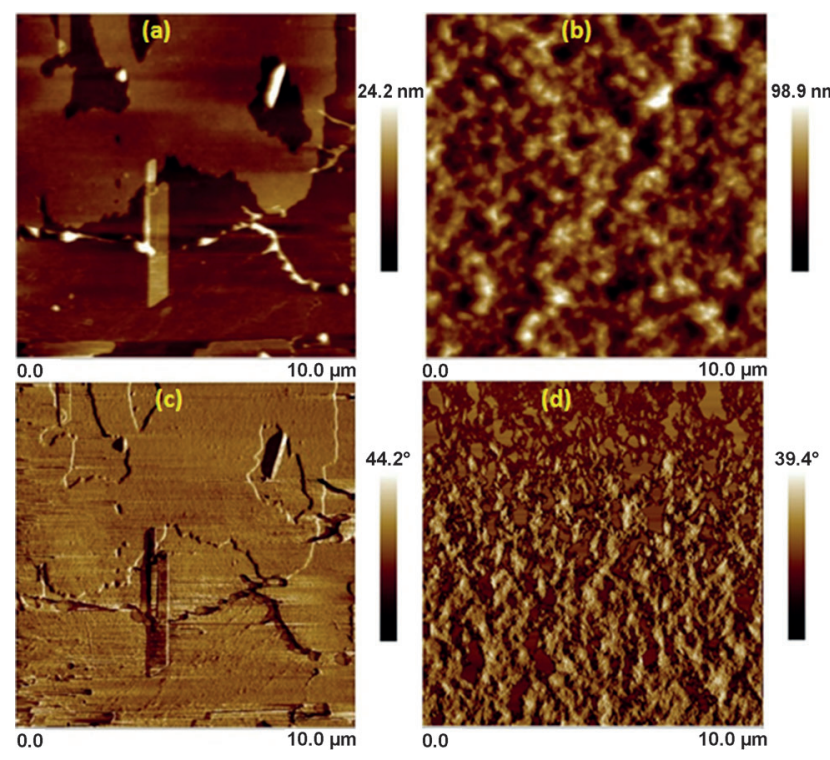

Figure 8. Height and phase AFM images for a thin film of as-cast B2 (a, c) and rr-P3HT-B2 blend (1:1 in o-dichlorobenzene), spun at $1000 \mathrm{rpm}$ for $1 \mathrm{~min}$ and annealed at $120^{\circ} \mathrm{C}$ for $5 \mathrm{~min}(b, d)$. charge transport in the thin film. ${ }^{[15]}$ Pristine B2 showed large crystalline domains with large grain boundaries.

After analyzing the crystalline morphology, we studied the charge transport properties of B2. In our first study, we used B2 as an active-channel semiconductor on octyltrichlorosilane $\left(\mathrm{OTS}-\mathrm{C}_{8}\right.$ ) and octadecyltrichlorosilane (OTS- $\mathrm{C}_{18}$ ) self-assembled monolayer-treated $\mathrm{Si}-\mathrm{SiO}_{2}$ substrates for organic field-effect transistor (OFET) devices using source and drain gold electrodes. Spun devices did not exhibit OFET mobility, whereas the thin film pre-annealed at $120^{\circ} \mathrm{C}$ exhibited charge-carrier mobility. The highest electron mobility measured was $3 \times$ $10^{-4} \mathrm{~cm}^{2} \mathrm{~V}^{-1} \mathrm{~s}^{-1}$ for the OTS- $\mathrm{C}_{18}$-treated substrate at $120^{\circ} \mathrm{C}$. The transfer characteristics of an B2-based OFET device are shown in Figure 9. The threshold voltage calculated from the transfer curve is $25 \mathrm{~V}$ and the on/off ratio is $10^{4}$.

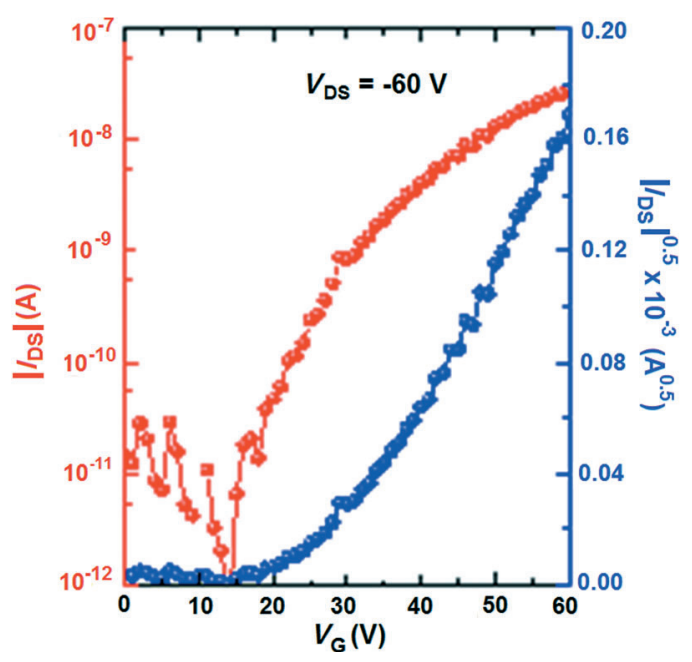

Figure 9. Transfer characteristics of top-gate, bottom-contact OFET devices using B2 as an active-channel semiconductor (channel width $2000 \mu \mathrm{m}$, length $20 \mu \mathrm{m})$

The main aim of designing and synthesizing B2 was to use it as a non-fullerene electron acceptor in organic solar cell devices, therefore we also studied the charge-transport properties of B2 using the time-of-flight photoconductivity (TOF-PC) method. ${ }^{[16,17]}$ The electron mobility of $\mathbf{B} 2$ is measured in a vertical diode structure (resembling the solar cell device structure) in order to confirm the charge-carrier transport capability in the blend. The details of the TOF-PC technique has been reported in an earlier publication. ${ }^{[18]}$ A simple ITO/B2(1200 nm)/ Al diode-based device was fabricated. The electron mobility was measured directly by exciting the B2 pristine film using a pulsed laser of wavelength $530 \mathrm{~nm}$ (pulse width $<5 \mathrm{~ns}$, repetition rate $1 \mathrm{~Hz}$ ) through the ITO electrode. A negative bias was applied to the ITO electrode in order to measure the electron mobility. The TOF photocurrent transients measured in a B2 film of $1200 \mathrm{~nm}$ thickness at room temperature for different negative bias voltages are shown in Figure 10, inset. The peak position of the transients, corresponding to the transit time of carriers was obtained and the respective charge mobility was calculated. The variation of charge mobility with the applied electric field is shown in Figure 10. It was observed that 


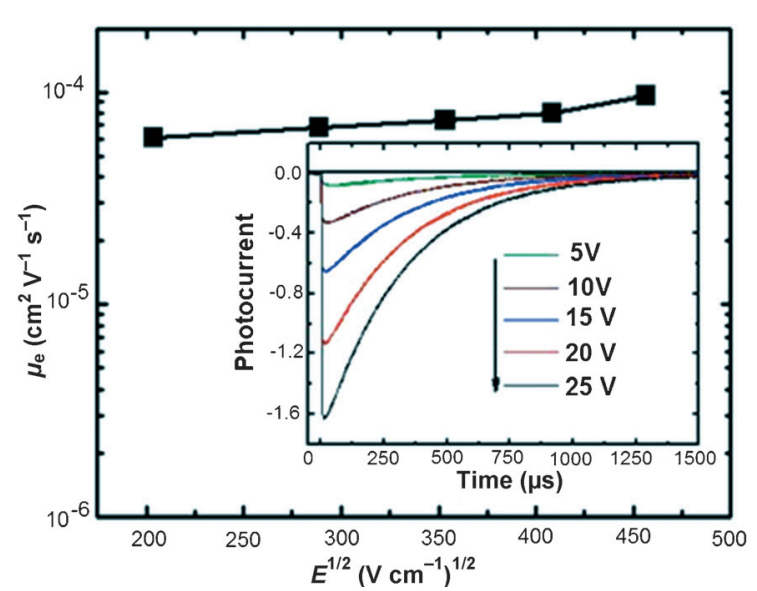

Figure 10. Variation of electron mobility with applied electric field; inset: current integrated TOF-PC transients for electrons measured at different applied voltages.

the charge mobility is weakly dependent on the applied electric field. The obtained electron mobility of B2 is approximately $1 \times 10^{-4} \mathrm{~cm}^{2} \mathrm{~V}^{-1} \mathrm{~s}^{-1}$ at an applied electric field of $2 \times 10^{5} \mathrm{~V} \mathrm{~cm}^{-1}$. The measured electron mobility using the TOF-PC method is consistent with the results obtained in the OFET. The main advantage of using an integrated TOF-PC method is that the device contact effect does not hamper the measurement and it also enables the measurement in thin films and disperse samples.

The material reported herein is evidently structurally simple and can be synthesized with ease, which are advantages compared to fullerene acceptors, for which high cost and lengthy purification procedures have been limiting factors. Although we achieved a high FF with moderate, albeit promising, PCE in solution-processable $\mathrm{BHJ}$ devices, this study provides an opportunity to explore new device strategies and B2 is worth adding to the molecular library of non-fullerene acceptors.

\section{Conclusions}

A novel, solution-processable, small-molecule chromophore, B2, was designed and developed as a non-fullerene electron acceptor for organic BHJ devices. B2 displayed excellent solubility, thermal stability, strong and broad absorption, appropriate energy levels that match those of an established electron donor moiety (rr-P3HT), and good electron mobility. The rrP3HT-B2 blend film formed structured, nanoscale interpenetrating networks, which is beneficial to charge separation and enhanced efficiency of the BHJ devices. Simple BHJ devices based on the blends of rr-P3HT and B2 exhibited PCEs as high as $1.16 \%$ with a high FF value of $54.3 \%$, which, in fact, is amongst the highest values reported for a single-junction $\mathrm{BHJ}$ device. B2 is an exciting structure with a clear potential to be included in the molecular library of $n$-type materials. This work demonstrated that the introduction of dye units in small molecules based on FL and NDI functionalities is a good strategy for developing new non-fullerene electron acceptors with promising performance in $\mathrm{BHJ}$ devices. The optimization of this work, as well as a search for novel designs of non-fullerene chromophores based on promising functionalities such as $\mathrm{FL}$ and NDI, is the subject of on-going research in our laboratories. Furthermore, such materials exhibit interesting chargetransport properties and promising electron mobilities in OFET and diode devices. The investigation of encouraging materials, of which B2 is an example, and acquiring promising optoelectronic and photovoltaic properties, are opportunities to develop novel motifs based on terminal NDI functionalities.

\section{Experimental Section}

\section{Materials and Instruments}

All reagents and chemicals were purchased from Sigma-Aldrich and used without further purification. The solvents used for reactions were obtained from Merck Speciality Chemicals (Sydney, Australia) and were used as provided. The synthesis of 4,9-dibromo2,7-dioctylbenzo[Imn][3,8]phenanthroline-1,3,6,8(2H,7H)-tetraone was reported previously. ${ }^{[10]}$ Unless otherwise specified, all ${ }^{1} \mathrm{H}$ and ${ }^{13} \mathrm{C}$ NMR spectra were recorded using a Bruker AV300 spectrometer at 300 and $75 \mathrm{MHz}$, respectively, or a Bruker AV200 spectrometer at 200 and $50 \mathrm{MHz}$, respectively. Chemical shifts $(\delta)$ are reported in parts per million (ppm). Thin-layer chromatography (TLC) was performed using $0.25 \mathrm{~mm}$ thick plates precoated with Merck Kieselgel $60 F_{254}$ silica gel and visualized using UV light $(254 \mathrm{~nm}$ and $365 \mathrm{~nm}$ ). Melting points were measured using a Gallenkamp MPD350 digital melting point apparatus and are uncorrected. High-resolution mass spectra experiments were carried out on a Bruker AutoFlex matrix-assisted laser desorption/ionisation (MALDI) time of flight (TOF) mass spectrometer. All UV/vis absorption spectra were recorded on a Hewlett Packard HP 8453 diode array UV/vis spectrophotometer. Thin films were spin-coated from o-dichlorobenzene at a spin speed of $2000 \mathrm{rpm}$ for $1 \mathrm{~min}$ onto cleaned glass slides. B2 was spin-coated from solutions at a concentration of $20 \mathrm{mg} \mathrm{mL}^{-1}$. P3HT-B2 blend solutions were prepared in the same manner as for devices, that is, P3HT (15 mg) and B2 $(15 \mathrm{mg})$ in $o$-dichlorobenzene (total volume of $1 \mathrm{~mL}$ ). Where specified, films were annealed at $120^{\circ} \mathrm{C}$ for $5 \mathrm{~min}$. Fluorescence spectra were recorded using a PerkinElmer LS50B fluorimeter. PESA measurements was recorded using a Riken Keiki AC-2 PESA spectrometer with a power setting of $5 \mathrm{nW}$ and a power number of 0.5 . Samples for PESA were prepared on clean glass substrates. The thermal stability of B2 was investigated using TGA and DSC. CV was performed in freshly distilled dichloromethane (stored over calcium hydride), with a supporting electrolyte of $n \mathrm{Bu}_{4} \mathrm{NPF}_{6}$ (electrochemical grade, $0.1 \mathrm{M}$ ), which was twice crystallized from ethanol before use. A glassy carbon electrode was used as a working electrode (ALS, Tokyo, Japan), which was polished with $0.05 \mu \mathrm{m}$ alumina on a felt pad, washed with distilled water followed by ethanol, and dried under an $\mathrm{N}_{2}$ stream before use. A Pt wire was used as a counter electrode and an $\mathrm{Ag}$ wire was used as a pseudo-reference electrode. Solutions were doped with an approximately equimolar amount of ferrocene as an internal reference. Voltammograms were measured at a scan rate of $50 \mathrm{mV} \mathrm{sec}^{-1}$. Redox potentials $\left(E_{1 / 2}\right.$ values) were taken as a half-way point between the forward and reverse peaks for each reversible redox process.

\section{Synthesis of 4-bromo-2,7-dioctyl-9-(octylamino)benzo[/mn] $[3,8]$ phenanthroline-1,3,6,8(2H,7H)-tetraone (1)}

4,9-Dibromo-2,7-dioctylbenzo[/mn][3,8]phenanthroline-

$1,3,6,8(2 \mathrm{H}, 7 \mathrm{H})$-tetraone $(2.51 \mathrm{~g}, 3.87 \mathrm{mmol})$ was added to a solution 
of octylamine ( $500 \mathrm{mg}, 3.87 \mathrm{mmol}$ ), sodium tert-butoxide (558 mg, $5.81 \mathrm{mmol})$ and palladium acetate $(112 \mathrm{mg}, 0.50 \mathrm{mmol})$ in toluene $(20 \mathrm{ml})$, followed by the addition of tri-tert-butylphosphine (404 mg, $2 \mathrm{mmol}$ ) at room temperature. The resulting suspension was heated at reflux overnight. Thin-layer chromatography indicated the disappearance of the starting dibromo derivative. The reaction mixture was filtered through celite followed by solvent evaporation. The crude residue was purified by silica gel column chromatography (hexane/ethyl acetate 19:1) to yield $870 \mathrm{mg}(32.3 \%)$ of 1 as a light pink solid. $R_{\mathrm{f}}=0.32$; m.p. $110-111^{\circ} \mathrm{C} ;{ }^{1} \mathrm{H}$ NMR $(300 \mathrm{MHz}$, $\left.\mathrm{CD}_{2} \mathrm{Cl}_{2}\right): \delta=10.09(\mathrm{t}, J=2.1 \mathrm{~Hz}, 1 \mathrm{H} ; \mathrm{NH}), 8.86(\mathrm{~s}, 1 \mathrm{H} ; \mathrm{NDI}), 8.28(\mathrm{~s}$, $1 \mathrm{H}$; NDI), 4.24-4.17 (t, J=7.2 Hz, 4H), 3.71-3.62 (m, $2 \mathrm{H}), 1.98-1.87$ $(\mathrm{m}, 2 \mathrm{H}), 1.82-1.71(\mathrm{~m}, 4 \mathrm{H}), 1.49-1.21(\mathrm{~m}, 30 \mathrm{H}), 0.98-0.87 \mathrm{ppm}(\mathrm{m}$, $9 \mathrm{H}) ;{ }^{13} \mathrm{C}$ NMR $\left(75 \mathrm{MHz}, \mathrm{CDCl}_{3}\right): \delta=165.8,161.9,161.7,161.3,151.7$, $138.1,128.5,127.2,123.3,123.2,121.3,120.4,120.1,99.7,53.4,43.4$, 41.4, 40.5, 31.8, 31.8, 29.4, 29.3, 29.2, 29.2, 28.0, 28.0, 27.2, 27.0, 22.6, $12.1 \mathrm{ppm}$; HRMS (MALDI-TOF): $\mathrm{m} / \mathrm{z}$ : calcd for $\mathrm{C}_{38} \mathrm{H}_{54} \mathrm{BrN}_{3} \mathrm{O}_{4}$ : $696.3370[M]^{+}$; found 696.3380 .

\section{Synthesis of 9,9'-(9,9-dioctyl-9H-fluorene-2,7-diyl)bis(2,7-di- octyl-4-(octylamino)benzo[Imn][3,8]phenanthroline- 1,3,6,8(2H,7H)-tetraone) (B2)}

(9,9-Dioctyl-9H-fluorene-2,7-diyl)diboronic acid (300 mg, $0.63 \mathrm{mmol}$ ) and compound $1(1.31 \mathrm{~g}, 1.89 \mathrm{mmol})$ were dissolved in 1,2-dimethoxyethane $(25 \mathrm{~mL})$ in a $100 \mathrm{~mL}$ round-bottom flask, followed by the addition of potassium carbonate $(261 \mathrm{mg}$, $1.89 \mathrm{mmol}$ ) at room temperature. The resulting suspension was stirred for $30 \mathrm{~min}$ and degassed by vacuum $/ \mathrm{N}_{2}$ purging $(3 \times)$ before $\left[\mathrm{Pd}\left(\mathrm{PPh}_{3}\right)_{4}\right] \quad(58 \mathrm{mg}, 0.05 \mathrm{mmol})$ was added. The resulting dark yellow suspension was stirred at $100^{\circ} \mathrm{C}$ overnight and the solvent was evaporated to afford a crude red solid, which was purified by silica gel column chromatography (hexane/ethyl acetate, 8:2) to afford B2 (685 mg, 67\%) as a bright red solid. $R_{\mathrm{f}}=0.38$; m.p. 230 $232^{\circ} \mathrm{C} ;{ }^{1} \mathrm{H}$ NMR $\left(300 \mathrm{MHz}, \mathrm{CD}_{2} \mathrm{Cl}_{2}\right): \delta=10.14(\mathrm{t}, J=2.2 \mathrm{~Hz}, 2 \mathrm{H} ; \mathrm{NH})$, $8.63(\mathrm{~s}, 2 \mathrm{H} ; \mathrm{NDI}), 8.31(\mathrm{~s}, 2 \mathrm{H}$; NDI), 8.97-7.93 (d, $J=7.1 \mathrm{~Hz}, 2 \mathrm{H})$, 7.49-7.42 (d, $J=6.8 \mathrm{~Hz}, 2 \mathrm{H}), 7.37(\mathrm{~s}, 2 \mathrm{H}), 4.23-4.22(\mathrm{t}, J=7.4 \mathrm{~Hz}$, $4 \mathrm{H}), 4.11-3.98(\mathrm{t}, J=7.4 \mathrm{~Hz}, 4 \mathrm{H}), 3.72-3.60(\mathrm{~m}, 4 \mathrm{H}), 2.09-1.98(\mathrm{~m}$, $4 \mathrm{H}), 1.89-1.81(\mathrm{~m}, 4 \mathrm{H}), 1.79-1.61(\mathrm{~m}, 4 \mathrm{H}), 1.49-1.19(\mathrm{~m}, 84 \mathrm{H})$, $1.11-1.06(\mathrm{~m}, 4 \mathrm{H}), 0.98-0.87(\mathrm{~m}, 12 \mathrm{H}), 0.83-0.79 \mathrm{ppm}(\mathrm{t}, J=7.1 \mathrm{~Hz}$, $12 \mathrm{H}) ;{ }^{13} \mathrm{CNMR}\left(75 \mathrm{MHz}, \mathrm{CDCl}_{3}\right): \delta=167.6,164.2,162.2,152.4$, $147.5,141.8,140.6,138.3,135.4,134.1,130.9,129.3,128.7,123.6$, $122.8,121.0,120.89,120.78,100.1,43.7,40.6,33.9,32.3,32.2,32.2$, 29.9, 29.8, 29.7, 29.6, 29.6, 28.5, 27.6, 27.5, 24.4, 23.1, 14.2, $12.7 \mathrm{ppm}$; MS (MALDI-TOF): $\mathrm{m} / \mathrm{z}$ : calcd for $\mathrm{C}_{105} \mathrm{H}_{148} \mathrm{~N}_{6} \mathrm{O}_{8}: 1621.2$ $[M]^{+}$; found: 1621.2 ; Elemental analysis calcd for $\mathrm{C}_{105} \mathrm{H}_{148} \mathrm{~N}_{6} \mathrm{O}_{8}$ (\%): C 77.74, H 9.20, N 5.18, O 7.89; found: C 77.72, H 9.16, N 5.15, O 7.86 .

\section{Fabrication and Characterization of BHJ Devices}

Indium tin oxide (ITO)-coated glass (10 ohms per square) was cleaned by sonication in a stirred solution of $5 \%(\mathrm{v} / \mathrm{v})$ Deconex $12 \mathrm{PA}$ detergent for $30 \mathrm{~min}$. The ITO-coated glass was then successively sonicated for $10 \mathrm{~min}$ each in distilled water, acetone, and isopropanol. The substrates were then subjected to a UV-ozone clean at $100^{\circ} \mathrm{C}$ for $10 \mathrm{~min}$ using a Novascan (Ames, USA) PSD-UVT UVozone cleaner with the platform set to maximum height. The intensity of the lamp was $>36 \mathrm{~mW} \mathrm{~cm}^{-2}$ at a distance of $10 \mathrm{~cm}$. At ambient conditions, the ozone output of the UV cleaner was $>50$ ppm. Aqueous solutions of PEDOT:PSS (Baytron P Al 4083, HC Starck, Munich, Germany) were filtered $(0.45 \mu \mathrm{m}$ polyvinylidene fluoride filter) and deposited onto glass substrates in air by spincoating (WS-400B-6NPP-lite single-wafer spin processor, Laurell
Technologies, North Wales, USA) at $4000 \mathrm{rpm}$ for $60 \mathrm{~s}$ to give a $35 \pm 5 \mathrm{~nm}$ thick layer. The PEDOT:PSS layer was then annealed on a hotplate in a glove box at $120^{\circ} \mathrm{C}$ for $10 \mathrm{~min}$. For BHJ devices, B2 and $\mathrm{P} 3 \mathrm{HT}$ (Nano-C, Westwood, USA) were separately dissolved in individual vials with magnetic stirring. Blend ratios and solution concentrations were varied to optimize device performance. The solutions were then combined, filtered $(0.45 \mu \mathrm{m}$ PTFE filter), and deposited by spin-coating (G3P spin coater, SCS, Indianapolis, USA) onto the ITO-coated glass substrates inside a glove box (with $\mathrm{H}_{2} \mathrm{O}$ and $\mathrm{O}_{2}$ levels both $<1 \mathrm{ppm}$ ). Film thicknesses were determined on identical samples using a $6 \mathrm{M}$ profilometer (Dektak, New Jersey, USA). The coated substrates were then transferred (without exposure to air) to a vacuum evaporator inside an adjacent $\mathrm{N}_{2}$-filled glove box. Samples were placed on a shadow mask in a tray. The area defined by the shadow mask gave device areas of exactly $0.09 \mathrm{~cm}^{2}$. Deposition rates and film thicknesses were monitored using a calibrated quartz thickness monitor inside the vacuum chamber. Aluminium (three pellets, 99.999\%, KJ Lesker, Jefferson Hills, USA), from an alumina-coated graphite boat, having thicknesses of $100 \mathrm{~nm}$, were evaporated onto the active layer by thermal evaporation at pressures $<2 \times 10^{-6}$ mbar.

The $J-V$ characteristics of the $\mathrm{BHJ}$ devices were measured under AM1.5G illumination at $100 \mathrm{~mW} \mathrm{~cm}^{-2}$ (SAN-El Electric XEC-301S solar simulator). The light intensity of the solar simulator was calibrated using a monosilicon detector (with a KG-5 visible color filter) to minimize the spectral mismatch. For IPCE measurements, the devices were tested in situ in a glovebox. IPCE data was collected using an Oriel $150 \mathrm{~W}$ lamp coupled to a monochromator and an optical fiber. The output of the optical fiber was focused to give a beam that was contained within the area of the device. IPCE data was calibrated with a standard, unfiltered Si cell. AFM topographic maps were measured directly on the active layer of P3HTB2 blends using an Asylum Research Santa Barbara, USA) MFP-3DSA instrument. The AFM measurements were run in the intermittent contact mode (tapping mode) using MicroMasch NSC18 tips (typical resonant frequency $\approx 100 \mathrm{kHz}$, typical probe radius $\approx 10 \mathrm{~nm}$, typical aspect ratio $3: 1$ ).

\section{Preparation of Thin-Film Transistors}

Top-contact, bottom-gate OTFT devices fabricated using $\mathrm{n}^{+}-\mathrm{Si}_{-} \mathrm{SiO}_{2}$ substrates where $\mathrm{n}^{+}-\mathrm{Si}$ and $\mathrm{SiO}_{2}$ work as gate electrode and gate dielectric, respectively. The thickness of thermally grown $\mathrm{SiO}_{2}$ layer was around $200 \mathrm{~nm}$ with a capacitance of approximately $17 \mathrm{nFcm}^{-2}$. The $\mathrm{Si}-\mathrm{SiO}_{2}$ substrate was cleaned with acetone and isopropanol. It was then immersed in a piranha solution $\left(\mathrm{H}_{2} \mathrm{SO}_{4} /\right.$ $\mathrm{H}_{2} \mathrm{O}_{2}$ ) for $20 \mathrm{~min}$, rinsed with deionized water, and kept in a vacuum oven at $120^{\circ} \mathrm{C}$ for $3 \mathrm{~h}$ with a few drops of OTS- $\mathrm{C}_{8} / \mathrm{OTS}-$ $\mathrm{C}_{18}$. It was then rinsed sequentially with chloroform, isopropanol, deionized water, and then dried with a stream of $\mathrm{N}_{2}$ gas. The B2 thin film was deposited from a $10 \mathrm{mg} \mathrm{mL}^{-1}$ solution in chloroform onto the alkylsilane-treated $\mathrm{Si}_{-} \mathrm{SiO}_{2}$ substrate by spin-coating. Subsequently, on top of the B2 active layer, a $100 \mathrm{~nm}$ thick Au thin film was deposited for source (S) and drain (D) electrodes through a shadow mask. For a typical OTFT device reported here, the S-D channel length $(L)$ and width $(W)$ was 20 and $2000 \mu \mathrm{m}$, respectively. The characteristics of the OTFT devices were measured at room temperature under $\mathrm{N}_{2}$ with a Keithley 4200 source meter. Measurements of the transistor characteristics were made using an Agilent B1500 A parameter analyzer. The two-probe field-effect mobility $(\mu)$ was calculated from the saturation regime of transfer characteristics. The standard transistor equation [Eq. (1)] in saturation mode was used to estimate the value of $\mu$ : 
$\mu=\frac{2 L}{W C_{i}}\left(\frac{\delta \sqrt{I_{D}}}{\delta V_{G}}\right)^{2}$

where $C_{\mathrm{i}}$ is the gate insulator capacitance.

\section{Time-of-Flight Photoconductivity Measurements}

The TOF-PC system consisted of a pulsed Nd:YAG laser-pumped optical parametric oscillator (Ekspla laser, pulse width $<5 \mathrm{~ns}, 1 \mathrm{~Hz}$ repetition rate), pulsed generator (SRS-DG535, Stanford Research Systems, USA), a dc voltage source, and a digital oscilloscope (Agilent Infiniium, $1 \mathrm{GHz}, 4 \mathrm{Gsa} \mathrm{s}^{-1}$ ). The device architecture used for the TOF photoconductivity measurements was ITO/active layer $(1200 \mathrm{~nm}) /$ Al. The laser of wavelength $530 \mathrm{~nm}$ was used to excite the sample through the ITO side of the device. The photocurrent under the influence of the applied electric field was monitored across a resistor $(R=2 \mathrm{k} \Omega)$ using an oscilloscope. Care was taken to ensure that the measurement was carried out in integrated mode, in which the time taken to collect the maximum charge corresponds to the carrier transit time $\left(t_{\mathrm{m}}\right)$. The TOF transients were measured by applying a different negative voltage to the ITO electrode in order to measure the electron mobility. The $t_{\mathrm{m}}$ value was extracted from the peak position of the photocurrent transients. The charge mobility $(\mu)$ was calculated using the relationship $\mu=$ $d^{2} / t_{m} V$, where $d$ is the film thickness and $V$ is applied voltage.

\section{Acknowledgements}

S.V.B. (RMIT) acknowledges financial support from the Australian Research Council (ARC), Australia, under a Future Fellowship Scheme (FT110100152). The CSIRO Division of Materials Science and Engineering, Clayton, Victoria is acknowledged for providing support through a visiting fellow position (A.G.). P.S. is thankful to the ARC Future Fellowship Scheme (FT130101337) at Queensland University of Technology, Brisbane, Queensland. S.V.B. (IICT) would like to thank the TAPSUN program for financial assistance under the project NWP0054.

Keywords: bulk heterojunction solar cells - fluorene naphthalenediimides $\cdot$ non-fullerene chromophores $\cdot$ solution processing

[1] a) D. Gupta, M. Bag, K. S. Narayan, Appl. Phys. Lett. 2008, 93, 163301 163303 ; b) A. K. Pandey, J. M. Nunzi, B. Ratier, A. Moliton, Phys. Lett. A 2008, 372, 1333-1336; c) J. U. Lee, J. W. Jung, J. W. Jo, W. H. Jo, J. Mater. Chem. 2012, 22, 24265-24283.

[2] J. B. You, L. T. Dou, K. Yoshimura, T. Kato, K. Ohya, T. Moriarty, K. Emery, C. C. Chen, J. Gao, G. Li, Y. Yang, Nat. Commun. 2013, 4, 1446.

[3] Y. Lin, Y. Li, X. Zhan, Chem. Soc. Rev. 2012, 41, 4245-4272.

[4] a) F. G. Brunetti, X. Gong, M. Tong, A. J. Heeger, F. Wudl, Angew. Chem. Int. Ed. 2010, 49, 532-536; Angew. Chem. 2010, 122, 542-546; b) F. G. Brunetti, R. Kumar, F. Wudl, J. Mater. Chem. 2010, 20, 2934-2948; c) A. Gupta, S. E. Watkins, A. D. Scully, T. B. Singh, G. J. Wilson, L. J. Rozanski, R. A. Evans, Synth. Met. 2011, 161, 856-863.

[5] R. Y. C. Shin, P. Sonar, P. S. Siew, Z. K. Chen, A. Sellinger, J. Org. Chem 2009, 74, 3293-3298.

[6] a) A. Mishra, P. Baüerle, Angew. Chem. Int. Ed. 2012, 51, 2020-2067; Angew. Chem. 2012, 124, 2060-2109; b) Y. Fang, A. K. Pandey, A. M. Nardes, N. Kopidakis, P. L. Burn, P. Meredith, Adv. Energy Mater. 2013, 3, 54-59; c) P. E. Schwenn, K. Gui, A. M. Nardes, K. B. Krueger, K. H. Lee, K. Mutkins, H. Rubinstein-Dunlop, P. E. Shaw, N. Kopidakis, P. L. Burn, P.
Meredith, Adv. Energy Mater. 2011, 1, 73-81; d) X. Zhang, Z. Lu, L. Ye, C. Zhan, J. Hou, S. Zhang, B. Jiang, Y. Zhao, J. Huang, S. Zhang, Y. Liu, Q. Shi, Y. Liu, J. Yao, Adv. Mater. 2013, 25, 5791-5797.

[7] a) Q. Yan, Y. Zhou, Y.-Q. Zheng, J. Pei, D. Zhao, Chem. Sci. 2013, 4, 43894394; b) P. Sonar, J. P. F. Lim, K. L. Chan, Energy Environ. Sci. 2011, 4, 1558-1574; c) Y. Lin, X. Zhan, Mater. Horiz. 2014, 1, 470-488.

[8] a) J. E. Anthony, Chem. Mater. 2011, 23, 583-590; b) P. Sonar, G. M. Ng, T. T. Lin, A. Dodabalapur, Z. K. Chen, J. Mater. Chem. 2010, 20, $3626-$ 3636; c) Y. Li, P. Sonar, L. Murphy, W. Hong, Energy Environ. Sci. 2013, 6, 1684-1710; d) Y. Lin, P. Cheng, Y. Li, X. Zhan, Chem. Commun. 2012, 48, 4773-4775; e) A. F. Eftaiha, J.P. Sun, I. G. Hill, G. C. Welch, J. Mater. Chem. A 2014, 2, $1201-1213$; f) Y. Lin, Y. Wang, J. Wang, J. Hou, Y. Li, D. Zhu, X. Zhan, Adv. Mater. 2014, 26, 5137-5142; g) Y. Lin, J. Wang, S. Dai, Y. Li, D. Zhu, X. Zhan, Adv. Energy Mater. 2014, 4, 1400420; h) J. T. Bloking, X. Han, A. T. Higgs, J. P. Kastrop, L. Pandey, J. E. Norton, C. Risko, C. E. Chen, J. L. Brédas, M. D. McGehee, A. Sellinger, Chem. Mater. 2011 23, 5484-5490; i) Y. Lin, Y. Li, X. Zhan, Adv. Energy Mater. 2013, 3, 724728; j) H. Patil, W. X. Zu, A. Gupta, V. Chellappan, A. Bilic, P. Sonar, A. Rananaware, S. V. Bhosale, S. V. Bhosale, Phys. Chem. Chem. Phys. 2014, 16, 23837-23842; k) A. M. Raynor, A. Gupta, H. Patil, A. Bilic, S. V. Bhosale, RSC Adv. 2014, 4, 57635-57638; I) S. Holliday, R. S. Ashraf, C. B. Nielsen, M. Kirkus, J. A. Röhr, C.-H. Tan, E. C. Fregoso, A.-C. Knall, J. R. Durrant, J. Nelson, I. McCulloch, J. Am. Chem. Soc. 2015, 137, 898-904.

[9] H. Patil, A. Gupta, A. Bilic, S. V. Bhosale, S. V. Bhosale, Tetrahedron Lett. 2014, 55, 4430-4432.

[10] H. Patil, A. Gupta, A. Bilic, S. L. Jackson, K. Latham, S. V. Bhosale, J. Electron. Mater. 2014, 43, 3243-3254.

[11] a) A. Gupta, A. Ali, A. Bilic, M. Gao, K. Hegedus, B. Singh, S. E. Watkins, G. J. Wilson, U. Bach, R. A. Evans, Chem. Commun. 2012, 48, 1889-1891; b) A. Gupta, V. Armel, W. Xiang, G. Fanchini, S. E. Watkins, D. R. MacFarlane, U. Bach, R. A. Evans, Tetrahedron 2013, 69, 3584-3592; c) R. J. Kumar, Q. I. Churches, J. Subbiah, A. Gupta, A. Ali, R. A. Evans, A. B. Holmes, Chem. Commun. 2013, 49, 6552-6554; d) A. Gupta, A. Ali, Th. B. Singh, A. Bilic, U. Bach, R. A. Evans, Tetrahedron 2012, 68, 9440 9447.

[12] Gaussian 09 (Revision D.01), M. J. Frisch, G. W. Trucks, H. B. Schlegel, G. E. Scuseria, M. A. Robb, J. R. Cheeseman, G. Scalmani, V. Barone, B. Mennucci, G. A. Petersson, H. Nakatsuji, M. Caricato, X. Li, H. P. Hratchian, A. F. Izmaylov, J. Bloino, G. Zheng, J. L. Sonnenberg, M. Hada, M. Ehara, K. Toyota, R. Fukuda, J. Hasegawa, M. Ishida, T. Nakajima, Y. Honda, O. Kitao, H. Nakai, T. Vreven, J. A. Montgomery, Jr., J. E. Peralta, F. Ogliaro, M. Bearpark, J. J. Heyd, E. Brothers, K. N. Kudin, V. N. Staroverov, R. Kobayashi, J. Normand, K. Raghavachari, A. Rendell, J. C. Burant, S. S. lyengar, J. Tomasi, M. Cossi, N. Rega, J. M. Millam, M. Klene, J. E. Knox, J. B. Cross, V. Bakken, C. Adamo, J. Jaramillo, R. Gomperts, R. E. Stratmann, O. Yazyev, A. J. Austin, R. Cammi, C. Pomelli, J. W. Ochterski, R. L. Martin, K. Morokuma, V. G. Zakrzewski, G. A. Voth, P. Salvador, J. J. Dannenberg, S. Dapprich, A. D. Daniels, Ö. Farkas, J. B. Foresman, J. V. Ortiz, J. Cioslowski, D. J. Fox, Gaussian, Inc., Wallingford CT, 2013.

[13] W. Ma, C. Yang, X. Gong, K. Lee, A. J. Heeger, Adv. Funct. Mater. 2005 $15,1617-1622$.

[14] J. H. Bannock, S. H. Krishnadasan, A. M. Nightingale, C. P. Yau, K. Khaw, D. Burkitt, J. J. M. Halls, M. Heeney, J. C. de Mello, Adv. Funct. Mater. 2013, 23, 2123-2129.

[15] G. Li, V. Shrotriya, J. Huang, Y. Yao, T. Moriarty, K. Emery, Y. Yang, Nat. Mater. 2005, 4, 864-868.

[16] M. J. Tan, W. P. Goh, L. Jun, G. Pundir, C. Vijila, C. Z. Kuan, ACS Appl. Mater. Interfaces 2010, 2, 1414-1420.

[17] C. Vijila, N. G. Meng, C. Z. Kuan, Z. Furong, C. S. Jin, J. Polym. Sci. Part B 2008, 46, 1159-1166.

[18] A. J. Campbell, D. D. C. Bradley, H. Antoniadis, Appl. Phys. Lett. 2001, 79, $2133-2135$.

Manuscript received: March 23, 2015

Revised: April 8, 2015

Accepted article published: April 21, 2015

Final article published: $\mathbf{\square} \mathbf{0}, 000$ 


\section{FULL PAPER}

No balls, please: A unique, non-fullerene, electron-accepting chromophore (B2) was designed, synthesized, and successfully used in solution-processable bulk heterojunction devices. A power conversion efficiency of $1.16 \%$ was achieved for primitive bulk hetero-

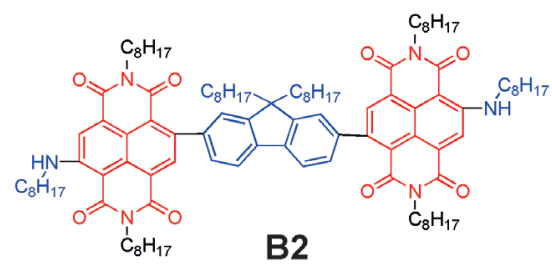
junction devices with a high fill factor of approximately $54 \%$. This fill factor is among the highest reported for nonfullerene acceptors.
Organic Electronics

Akhil Gupta, ${ }^{*}$ Xizu Wang, Doli Srivani, Ben Alford, Vijila Chellappan, Ante Bilic, Hemlata Patil, Lathe A. Jones, Sidhanath V. Bhosale, ${ }^{*}$ Prashant Sonar,* Sheshanath V. Bhosale*

An Electron-Accepting Chromophore Based on Fluorene and

Naphthalenediimide Building Blocks for Solution-Processable Bulk Heterojunction Devices 